\title{
Electron paramagnetic resonance spectroscopic studies of iron and copper proteins
}

\author{
Fatai A. Taiwo \\ School of Pharmacy and Pharmaceutical Sciences, De Montfort University, The Gateway, \\ Leicester LE1 9BH, UK \\ E-mail: ttaiwo@dmu.ac.uk
}

In memory of Martyn C.R. Symons, FRS

\begin{abstract}
Transition metal (d-group) ions are widespread in nature, essential for structural characteristics and mechanistic specificity of many proteins. Iron and copper are the two most prevalent metals in proteins responsible for the storage and transport of molecules, ions, and electrons. Electron paramagnetic resonance (EPR) spectroscopy has been extensively used for the determination of these metal ions without extensive disruption of the native protein moiety. It also detects variations in coordination geometry due to ligand substitutions as well as multiple valencies of the same metal. This review highlights the unique application of EPR spectroscopy to the study of iron and copper in biological systems. Mention is made of a select number of other metalloproteins.
\end{abstract}

Keywords: Iron, copper, EPR, ESR, metalloproteins

\section{Introduction}

In this overview, the way in which EPR spectroscopy has been of use in the study of selected metalloproteins is presented. The dominant metals are iron and copper, being most abundant in biological systems. The more minor species like manganese, cobalt, and molybdenum are mentioned also in their roles in metalloprotein chemistry. Most of the discussion is on metal ions complexed in protein moieties, in contrast to hydrated 'free' metal ions to which water molecules are bonded as ligands. Since ligands form basis of coordination geometry, hydrated ions are symmetric by default while protein-bound metals have variable symmetries. Spectroscopic signatures of the metal ions would depend on types and numbers of ligands attached even if their oxidation states remain the same. These species are distinguishable by EPR spectroscopy through interaction of electron spin and their different orbital arrangements.

The EPR spectroscopic act rests essentially on the energy difference, $\Delta E$, between the two possible spin states $\mathrm{Ms}=+1 / 2$ and $\mathrm{Ms}=-1 / 2$ of an electron when an external magnetic field is applied. Under appropriate instrumental conditions, transition between these two levels can be induced by applying an oscillating electromagnetic field of resonant energy equal to $\Delta E$, to the electron. The value of $\Delta E$ depends on the environment of the hypothetical 'free' electron. It needs to be stressed that the electron must not be paired as pairing will annul the magnetic moments of either electron, both being aligned 
in mutually opposite spins. Two very important parameters are the spectroscopic index ( $g$-values), and hyperfine constants ( $A$-values), both of which represent signatures for different paramagnetic species. The $g$-value is a measure of electronic interaction between the unpaired electron and the applied magnetic field. For the 'free' electron, the $g$-value $\left(g_{\mathrm{e}}\right)$ is 2.0023 , called 'free spin'. Because there are several factors associated with the electron, e.g., the nucleus, orbital motion, and other electrons, true $g$-values are different from $g_{\mathrm{e}}$. Hyperfine coupling constants are measures of interactions between the electron and its nucleus and also nuclei of adjacent atoms directly bonded or further away. Further treatment of theory of EPR spectroscopy can be found in the literature [1,2].

\section{Iron proteins}

Iron is the single most abundant metal in biological systems, occurring mostly in respiratory proteins. Haemoglobin and myoglobin are two most abundant iron-containing proteins. The strategic presence of iron in the haem facilitates transportation and storage of oxygen by the two proteins, respectively. Reversible binding by carbon dioxide in the forms of carbonic acid and carbamino compounds in concert with a pH differential (Bohr effect) facilitate the gaseous exchange mechanisms through the lungs. Both proteins are structurally similar except that haemoglobin is a tetramer of the myoglobin-type structure. Other iron-containing proteins found in large amounts are ferritin, transferrin, and haemosiderin. $\mathrm{Cy}-$ tochromes and cytochrome oxidases are iron-containing proteins responsible for electron transport in the mitochondria. Several iron proteins are found in relatively smaller amounts.

Detection of iron by EPR spectroscopy depends in principle on the presence of unpaired electrons in resting or intermediate reactive species. As a rule of thumb, electronic configurations of d-group metal ions which can be detected by EPR spectroscopy would contain $\mathrm{d}^{1}, \mathrm{~d}^{3}, \mathrm{~d}^{5}, \mathrm{~d}^{7}$, and $\mathrm{d}^{9}$ terms. The presence of an odd number of electrons results in at least one unpaired electron being available for EPR transitions. [3]

Iron in the monovalent state $\mathrm{Fe}^{\mathrm{I}}$ has the $\mathrm{d}^{7}$ configuration with spin value $s=1 / 2$ arising from a distribution into two sets of non-degenerate d-orbitals to give $\mathrm{t}_{2 \mathrm{~g}}^{6} \mathrm{e}_{\mathrm{g}}^{1}$. Promotion of the residual $4 \mathrm{~s}^{1}$ electron to the $3 \mathrm{~d}$-orbital however would require such a large amount of energy that constituent protein moiety close to the iron may be affected structurally. If at all possible, the EPR spectrum would comprise a doublet of lines arising from a spin value $s=1 / 2$. Divalent $\mathrm{Fe}^{\mathrm{II}}$ specie is a $\mathrm{d}^{6}$ configuration with two possibilities of spin states; a low spin $\mathrm{t}_{2 \mathrm{~g}}^{6} \mathrm{e}_{\mathrm{g}}^{0}$ and a high spin $\mathrm{t}_{2 \mathrm{~g}}^{4} \mathrm{e}_{\mathrm{g}}^{2}$ depending on crystal field splitting energy of associated ligands. Their respective spin values are hence $s=0$ and $s=2$, both of which are not observable by EPR. Detection of nitrous oxide by binding to ferro-hemoproteins is due to formation of the $\mathrm{Fe}-\mathrm{N}=\mathrm{O}$ complex in which nitrogen p-orbital overlaps with the Fe d-orbital such that the unpaired electron is mainly localised on the NO ligand. The iron has a spin $3 / 2[4,5]$.

The trivalent state $\mathrm{Fe}^{\mathrm{III}}$ has $\mathrm{d}^{5}$, a most stable configuration with possibilities of two spin states; low spin $\mathrm{t}_{2 \mathrm{~g}}^{3} \mathrm{e}_{\mathrm{g}}^{2}$ and high spin $\mathrm{t}_{2 \mathrm{~g}}^{5} \mathrm{e}_{\mathrm{g}}^{0}$. Their respective spin values of $5 / 2$ and $1 / 2$ are both detectable by EPR, exhibiting many spectral characteristics depending on ligands, molecular environment, and solvent medium. The tetravalent state $\mathrm{Fe}^{\mathrm{IV}} \mathrm{d}^{4}, \mathrm{t}_{2 \mathrm{~g}}^{4} \mathrm{e}_{\mathrm{g}}^{0}$ has a spin value $s=1$ which is not detectable by EPR. This is the form of Fe in the oxo- complex of haemoglobin after its reaction with hydrogen peroxide, known as ferryl species. Proof of formation of the ferryl $\left[\mathrm{Fe}^{\mathrm{IV}}=\mathrm{O}\right]$ specie by EPR spectroscopy was obtained from its one-electron reduction to the easily detectable $\mathrm{Fe}^{\mathrm{III}}$ derivative [6]. The $s=2$ state may be expected from an energy equalisation of the $t_{2 g}$ and $e_{g}$ levels so that four unpaired electrons are singly filled into four of the five degenerate energy levels $\Delta=0$. This however is purely hypothetical. Pairing of the four electrons in two levels to give $s=0$ is also not possible. 


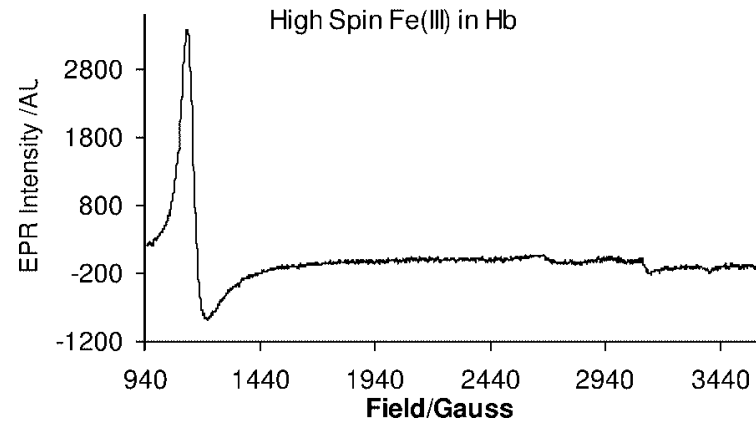

(a)

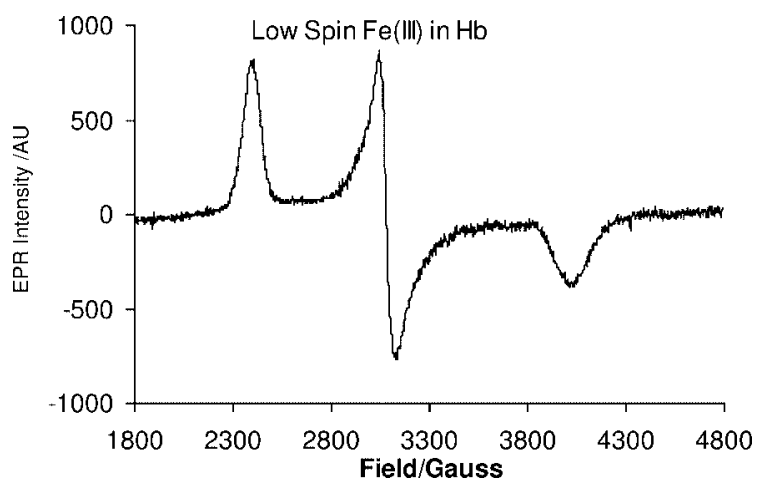

(b)

Fig. 1. First derivative X-band EPR spectrum for methaemoglobin showing (a) high spin features of $\mathrm{Fe}^{\mathrm{III}}$ at $g=6$, low field, (b) low spin $\mathrm{Fe}^{\mathrm{II}}$ features at $g=2.855,2.226$, and 1.794 , mid-field.

Pentavalent iron $\mathrm{Fe}^{\mathrm{V}}, \mathrm{d}^{3} ;\left(\mathrm{t}_{2 \mathrm{~g}}^{3} \mathrm{e}_{\mathrm{g}}^{0}\right)$ has a spin value $s=3 / 2$ and its EPR spectrum has been observed mostly in inorganic oxo-complexes [7]. It is also the constituent of compound I intermediate obtained during the catalytic turnover of catalase, horseradish peroxidase, and cytochrome c peroxidase [7]. The alternative configuration $\mathrm{d}^{1}\left(\mathrm{t}_{2 \mathrm{~g}}^{1} \mathrm{e}_{\mathrm{g}}^{0}\right)$ in which the $4 \mathrm{~s}$ orbital is full, with a spin value of $s=1 / 2$ will also give an EPR spectrum but this is not favoured on energy considerations. Under very powerful oxidising conditions the hexavalent specie $\mathrm{Fe}^{\mathrm{IV}}$ may be obtained. With a configuration of $\mathrm{d}^{0}\left(\mathrm{t}_{2 \mathrm{~g}}^{0} \mathrm{e}_{\mathrm{g}}^{0}\right)$ and $\operatorname{spin} s=0$, an EPR spectrum is not expected. However the one electron adduct of oxyhaemoglobin has been detected by EPR spectroscopy with well resolved features indicating formation of $\mathrm{FeO}_{2}^{-}$in which an electron is added to the oxygen antibonding orbital. The features are so specific that $\mathrm{FeO}_{2}^{-}$units of $\alpha$ - and $\beta$-chains are distinguishable by characteristic EPR spectral parameters. Proton addition to $\mathrm{FeO}_{2}^{-}$species results in oxidation to the $\mathrm{Fe}^{\mathrm{III}}$ state as in methaemoglobin with different $g$ - and $A$ - values depending on the state of thermal relaxation [8].

Figure 1 shows typical EPR spectra for $\mathrm{Fe}^{\mathrm{III}}$ derivatives of haemoglobin in high and low spin spectroscopic states. The distinguishing features are the field positions at which resonance occurs. More precisely these are translated to $g$-values, considering variations of frequencies of microwave applied. The X-band spectrum for high spin state shows strong features at $g=6$ and a complimentary weak absorption at close to free spin, $g=2$. High spin $\mathrm{Fe}^{\mathrm{III}}$ may also show up at $g=4.3$ due to quantum mechanical mixed states. For the low spin form three lines can be observed at $g$-values of 2.82, 2.20, and 1.67, all of which arise from the same transition in axial symmetry exhibiting $g_{x}, g_{y}$, and $g_{z}$ orthogonal character of a tensor. As the ligand at the sixth coordination position changes, including $\mathrm{pH}$ effects, the symmetry of the central metal iron also changes creating distortions from rhombic to axial symmetry. This is a consequence of Jahn-Teller effect. If the $g$-values of low spin $\mathrm{Fe}^{\mathrm{III}}$ spectra were plotted to display $g_{x}$ in a linear format, the $g_{y}$ and $g_{z}$ have been shown to follow a trend as shown in Fig. 2 [6]. The convergence point of all $g$-values is at 'free spin'. This therefore is a display of EPR spectroscopic parameters as geometry changes from axial to rhombic symmetry.

Two amazing proteins ferritin and haemosiderin, have capacity for storage of iron (up to 500) in the form of $\mathrm{Fe}^{\mathrm{III}}$ with gated channels for release as per demand. The stored species is a special form of $\mathrm{Fe}_{2} \mathrm{O}_{3}$, which in nature is the hard mineral oxide of iron. Because of a high concentration of $\mathrm{Fe}^{\mathrm{III}}$ in the storage 'cluster', EPR spectra of ferritin and hemosiderin are broad lines unlike those observed for dilute solutions of haemoproteins like haemoglobin and myoglobin [9]. 


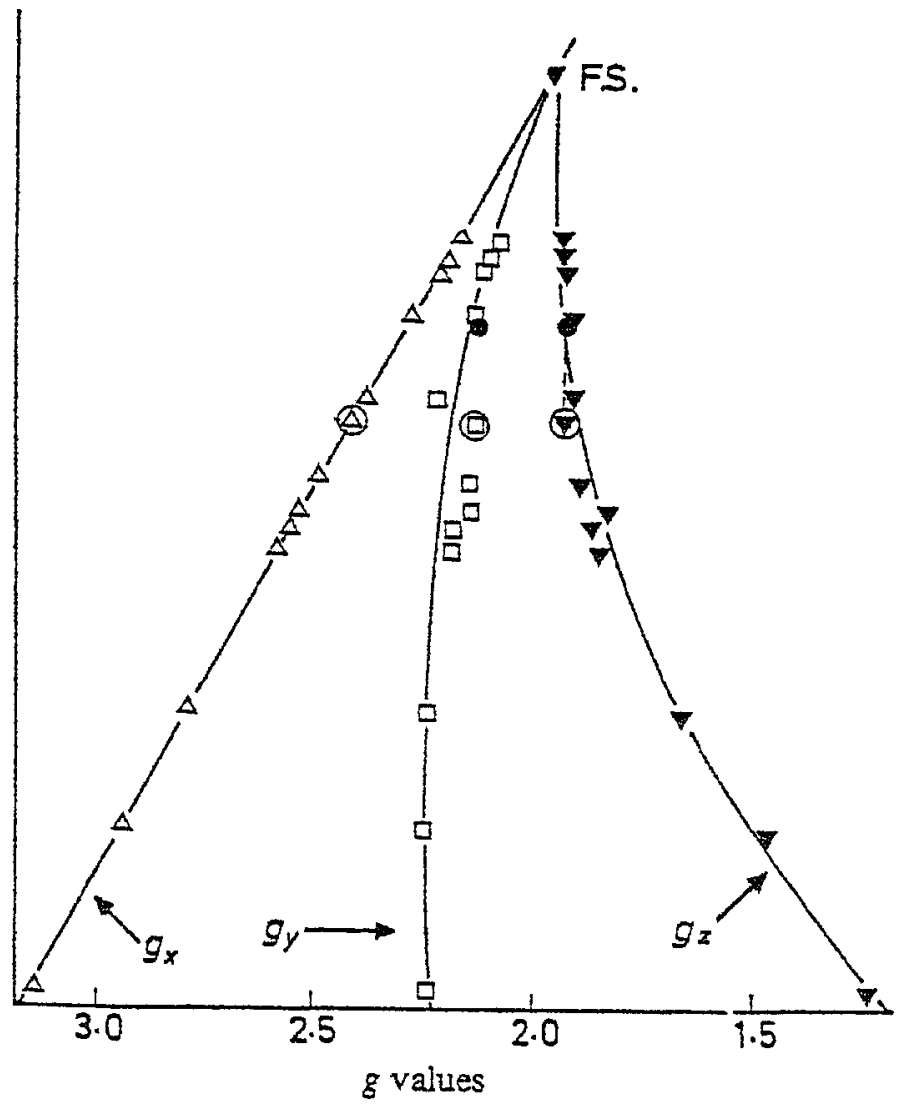

Fig. 2. Trends in the $g$-values for a range of low spin $\mathrm{Fe}^{\mathrm{III}}$ complexes showing convergence of $g$-values to 'free spin'.

Because of the very large number of red cells in circulation, and their high turnover, there is potential for a high amount of iron to be present in circulation as hematin or free iron mostly in the $\mathrm{Fe}^{\mathrm{III}}$ form. Occurrence of hydrogen peroxide in general bodily fluids therefore potentiates formation of hydroxyl radicals via the Fenton reaction:

$$
\mathrm{Fe}^{\mathrm{II}}+\mathrm{H}_{2} \mathrm{O}_{2} \rightarrow \mathrm{Fe}^{\mathrm{III}}+{ }^{-} \mathrm{OH}+{ }^{\cdot} \mathrm{OH} .
$$

The hydroxyl radical is usually detected by spin trapping and used also as a quantitative measure of free iron or hydrogen peroxide in very small biological samples that are not amenable to extensive analytical procedures [13].

\section{Copper proteins}

Naturally abundant copper proteins include cerulloplasmin, hemocyanin, and $\mathrm{Cu} / \mathrm{Zn}$ superoxide dismutase. The $\mathrm{Cu}^{\mathrm{II}}, \mathrm{d}^{9}$ species contain an odd number of electrons to give a spin $s=1 / 2$ and therefore EPR transitions. With a magnetic moment $M_{\mathrm{I}}=3 / 2, \mathrm{Cu}^{\mathrm{II}}$ gives a spectrum comprising a quartet of lines. Major parameters for copper in proteins are the parallel and perpendicular features arising from an axial type spectrum defined by $g_{/ /}$and $g_{\perp}$ and $A_{/ /}$and $A_{\perp}$. Typical spectra for $\mathrm{Cu}^{\mathrm{II}}$ at $77 \mathrm{~K}$ are shown in Fig. 3 


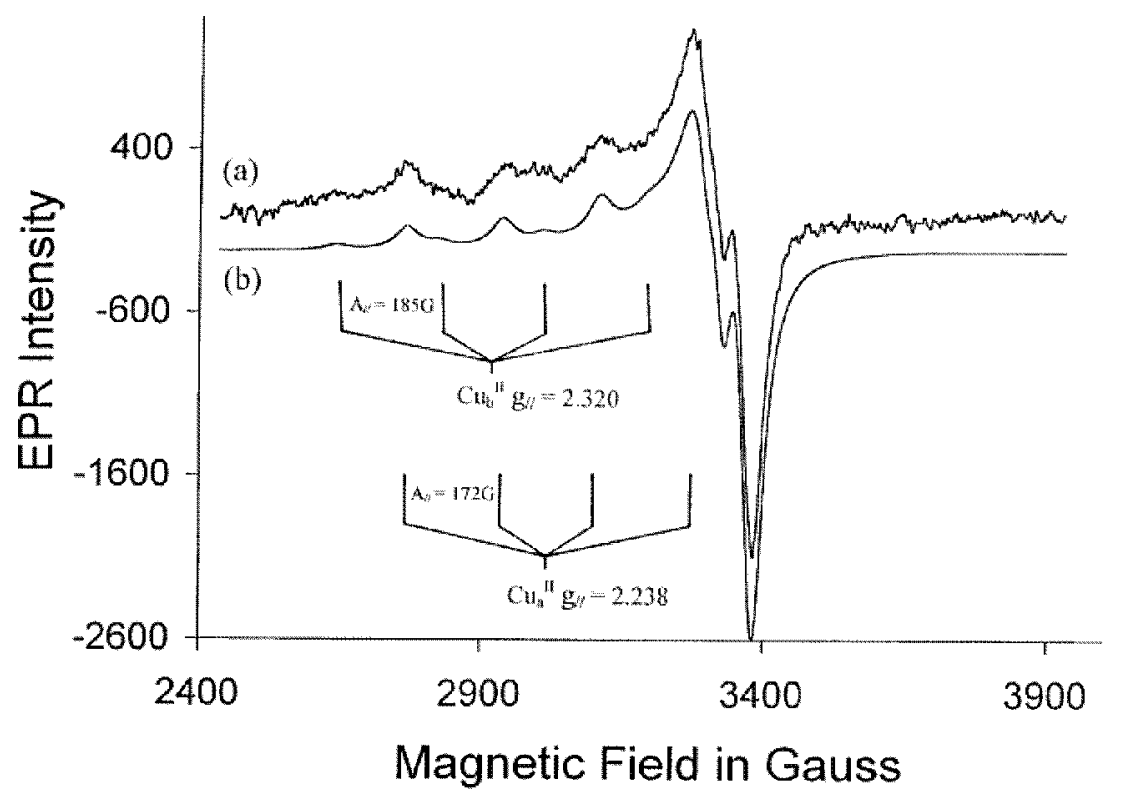

Fig. 3. First derivative EPR spectra for $\mathrm{Cu}^{\mathrm{II}}$ showing different $g$-values and $A$-values for different structural environments.

[10]. It is important to note differences in EPR parameters of the two copper species indicating different $\mathrm{Cu}^{\mathrm{II}}$ centres by virtue of respective ligand environments. Some works have identified copper centres as type 1, type 2 and type 3 [11]. The type 1 has an intense blue coloration and a high extinction coefficient in its electronic absorption spectrum. The type 2 has a weaker absorption spectrum and higher hyperfine splitting constants ( $A$-values) in its EPR spectrum than type 1. Type 3 comprises pairs of copper so close there is antiferromagnetic coupling and therefore not detectable by EPR spectoroscopy. On a plot of $A_{/ /}$ vs $g_{/ /}$types 1 and 2 are differentiated into groups as shown in Fig. 4. Like iron the copper is complexed within protein moieties such that hydrated copper ion is not observed except where there has been denaturation in which the metal drops free of the protein. In such a case spectroscopic parameters would be different. A common ligand is nitrogen, usually from the side group of a histidine residue. Nitrogen hyperfines would therefore show on the copper peaks.

Spectra for $\mathrm{Fe}^{\mathrm{III}}$ show no hyperfine splitting, since ${ }^{57} \mathrm{Fe}$ is in very low abundance $(2.15 \%)$. However, since all the others such as ${ }^{63} \mathrm{Cu}$ (abundance 69\%), have well defined hyperfine splitting, the absence of any splitting is a good signature for $\mathrm{Fe}^{\mathrm{III}}$ in biological conditions. The quartet of lines arising from $s=1 / 2, M_{\mathrm{I}}=3 / 2$, is generally only resolved for the parallel features which come at low magnetic fields (high $g$-values), leaving the perpendicular feature unresolved with an intense peak representative of a combination of the $x$ and $y$ components. It should be noted that if comparison of data for a range of $\mathrm{Cu}^{\mathrm{II}}$ complexes is required, corrections should be made for the orbital paramagnetism that reduces the $g$-shifts. This is indicated in Fig. 4 [12]. The two copper lines embrace the data for a wide range of square planar $\mathrm{Cu}^{\mathrm{II}}$ complexes. The lowest line covers the data for $\mathrm{Cu}^{\mathrm{II}}$ complexes that are induced by the protein structure to move towards the tetrahedral structure usually of $\mathrm{Cu}^{\mathrm{I}}$ complexes.

\subsection{Binuclear copper}

This is best exemplified by hemocyanin, the respiratory protein in molluscs and arthropods comprising two coppers per oxygen binding site. Gaseous exchange is facilitated by reversible redox reactions 


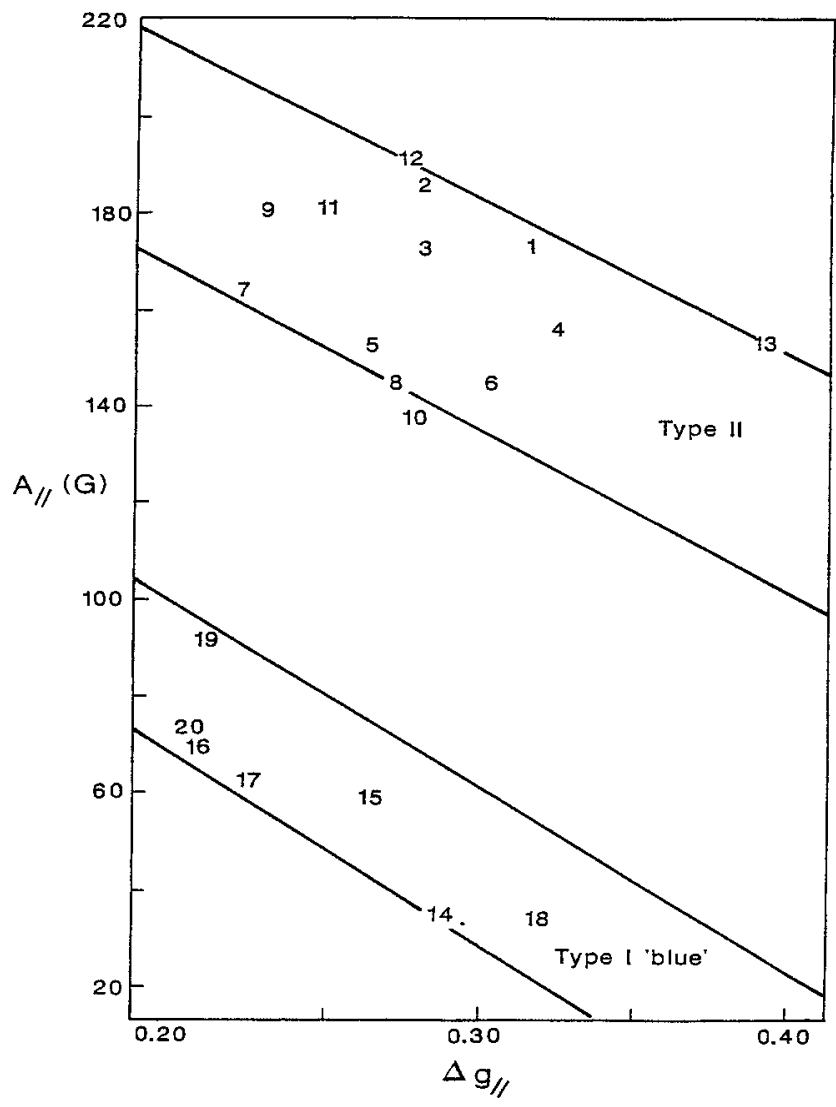

Fig. 4. Plots showing the grouping of EPR parameters for types 1 and $2 \mathrm{Cu}^{\mathrm{II}}$ species. Numbers refer to the number of data points in the cluster.

during which the two coppers cycle between $\mathrm{Cu}^{\mathrm{I}}$ and $\mathrm{Cu}^{\mathrm{II}}$ states simultaneously [12]. In the oxygenated state both coppers are $\mathrm{Cu}^{\mathrm{II}}$ and there is considerable overlap of d-orbitals resulting in antiferromagnetic coupling between the unpaired electrons in those orbitals. The effective spin value is zero, hence no EPR transitions. This is a special case where $\mathrm{Cu}^{\mathrm{II}}$ is not detectable. On selective reduction of one of the coppers a mixed valence state is obtained allowing detection of the $\mathrm{Cu}^{\mathrm{II}}$ in the presence of $\mathrm{Cu}^{\mathrm{I}}$ [12].

\section{2. $\mathrm{Cu} / \mathrm{Zn} S O D$}

The role of this enzyme, like other superoxide dismutases Fe SOD and Mn SOD, is to convert $\mathrm{O}_{2}^{-}$ to hydrogen peroxide and oxygen. It is not always appreciated that $\mathrm{O}_{2}^{-}$is a stable radical anion and that solutions thereof in aqueous alkali are also very stable. However in neutral solution some $\mathrm{HO}_{2}^{-}$ radicals are formed. These are very reactive hence an enzyme that converts $\mathrm{O}_{2}^{--}$into $\mathrm{O}_{2}$ and $\mathrm{H}_{2} \mathrm{O}_{2}$ is very valuable. It is important to note that whilst $\mathrm{H}_{2} \mathrm{O}_{2}$ is a powerful electron acceptor, $\mathrm{HO}_{2}^{-}$is a powerful electron donor. In this enzyme the mechanism of catalysis rest mainly on the redox capability of copper which moves between +2 and +1 oxidation states during enzyme turnover. The zinc ion which is neither an electron donor nor electron acceptor is thought to play a purely structural role to support the protein. The question might be asked however if the zinc does not remotely influence the oxidation potential of 


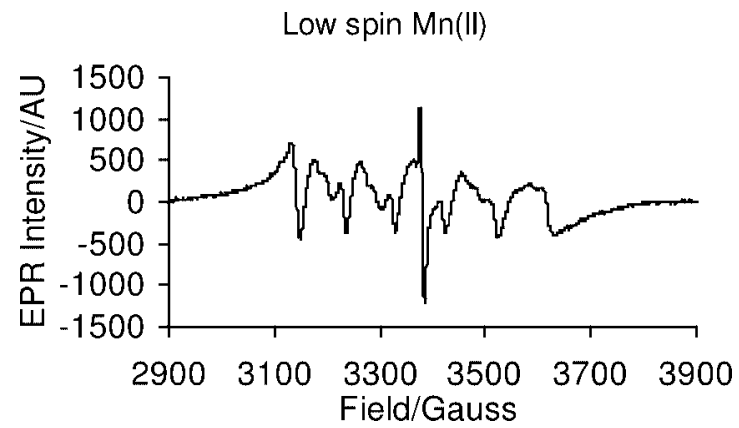

Fig. 5. First derivative X-band EPR spectrum for $\mathrm{Mn}^{\mathrm{II}}$ centres in tobacco leaf, showing characteristic 6-line features arising from $s=1 / 2$ and $M_{\mathrm{I}}=5 / 2$.

the copper within a structural motif of in the enzyme for specific reactivity. Otherwise replacement of zinc by a suitably inactive metal would not affect the enzymology of the copper enzyme.

\section{Manganese proteins}

Manganese occurs in much smaller amounts than iron and copper in nature. As a contributor to electron transfer in the oxygen evolving photosystem, manganese is widespread in plants. Its presence is easily determined by EPR, based on $\mathrm{Mn}^{\mathrm{II}}, \mathrm{d}^{5}, s=5 / 2$. On interaction with the nucleus $M_{\mathrm{I}}=1$, a characteristic set of six isotopic lines is obtained, centred close to free spin. Figure 5 shows $\mathrm{Mn}^{\mathrm{II}}$ lines obtained from tobacco leaves at $77 \mathrm{~K}$ [13]. The mitochondrial superoxide dismutase enzyme contains manganese, though this is far less abundant than the copper-zinc enzyme. The EPR spectrum for MnSOD shows features ascribed to high spin. $\mathrm{Mn}^{\mathrm{III}}$ and $\mathrm{Mn}^{\mathrm{IV}}$ and probably higher oxidation states are reported to be present in catalases $[14,15]$.

\section{Interaction of Fe with hydrogen peroxide}

Interaction of hydrogen peroxide with metal irons is generally known to produce hydroxyl radicals.

$$
\mathrm{Fe}^{\mathrm{II}}+\mathrm{H}_{2} \mathrm{O}_{2} \rightarrow \mathrm{Fe}^{\mathrm{III}}+-\mathrm{OH}+\cdot \cdot \mathrm{OH}
$$

Following the discovery by Fenton over a century ago, that $\mathrm{H}_{2} \mathrm{O}_{2}$ in the presence of $\mathrm{Fe}^{\mathrm{II}}$ ions reacted with a range of water-soluble organic compounds and induced extensive damage, there have been different mechanisms proposed. The most applicable in general, is the Haber-Wiess mechanism. This involves a one step oxidation to $\mathrm{Fe}^{\mathrm{III}}$ with formation of the hydroxyl radicals;

$$
\mathrm{Fe}^{\mathrm{II}}+\mathrm{H}_{2} \mathrm{O}_{2} \rightarrow\left[\mathrm{Fe}^{\mathrm{III}}-\mathrm{OH}\right]+\cdot \mathrm{OH} \text {. }
$$

A less well recognized, the Bray-Gorin mechanism, involves two electron transfer as in an oxygen atom transfer;

$$
\mathrm{H}_{2} \mathrm{O}_{2}+\mathrm{R}_{2} \mathrm{~S} \rightarrow \mathrm{R}_{2} \mathrm{SO}+\mathrm{H}_{2} \mathrm{O}
$$


It is of interest to compare the effect of these two alternative mechanisms with respect to interaction with haemoglobin. In the Haber-Weiss mechanism the $\mathrm{H}_{2} \mathrm{O}_{2}$ moves freely into the channel that leads to the $\mathrm{Fe}^{\mathrm{II}}$ ion, since it is a water look-alike. This reacts to give hydroxyl radicals which may add to the haem or damage sections of the protein that are close to its site of formation.

In marked contrast the Bray-Gorin mechanism involves the formation of ferryl iron;

$$
\mathrm{Fe}^{\mathrm{II}}+\mathrm{H}_{2} \mathrm{O}_{2} \rightarrow\left[\mathrm{Fe}^{\mathrm{IV}}=\mathrm{O}\right]+\mathrm{H}_{2} \mathrm{O} .
$$

Since ferryl is a major product, this is surely a very important process. However it is often argued that a two step mechanism is responsible:

$$
\begin{aligned}
& \mathrm{Fe}^{\mathrm{II}}+\mathrm{H}_{2} \mathrm{O}_{2} \rightarrow\left[\mathrm{Fe}^{\mathrm{III}}=\mathrm{OH}\right]+\mathrm{OH}, \\
& {\left[\mathrm{Fe}^{\mathrm{III}}=\mathrm{OH}\right]+\cdot \mathrm{OH} \rightarrow\left[\mathrm{Fe}^{\mathrm{IV}}=\mathrm{O}\right]+\mathrm{H}_{2} \mathrm{O} .}
\end{aligned}
$$

In our view the one step process is preferable. Our work on this reaction showed the rapid formation of $\mathrm{Fe}^{\mathrm{IV}}$ which was later reduced to $\mathrm{Fe} \mathrm{eII}^{\mathrm{III}}$, as in methaemoglobin, by one electron addition at $77 \mathrm{~K}$. Rapid freeze methods did not show any intermediate $\mathrm{Fe}^{\mathrm{III}}$ prior to formation of $\mathrm{Fe}^{\mathrm{IV}}[6]$. On the reactivity of ferroproteins with hydrogen peroxide, it has been shown that hydroxyl radical is not a primary product. Hydrogen peroxide first induces denaturation of haemoglobin and myoglobin to release chelatable iron which then undergoes Fenton reaction with excess peroxide to form hydroxyl radicals [16]. The hydroxyl radical is usually measured by use of spin traps to form more stable adducts which have characteristic EPR features. This reaction is of practical importance in the quantitative determination of free iron or hydrogen peroxide in small biological samples that are not amenable to extensive analytical procedures.

\section{Cobalamin}

Cobalamin, also known as vitamin $\mathrm{B}_{12}$, is an organic molecule in which a cobalt is 4-coordinated at the centre of a corrin group, a smaller haem-type structure with 4 nitrogen donor positions. The fifth position is $\mathrm{N}$-linked to a dimethylbenzimidazole to which is attached a ribose-3-phosphate O-linked to aminopropanol. The sixth position is occupied by $5^{\prime}$-deoxyadenosyl, but can be replaced by other substitutes as in the different derivatives of cobalamin.

The $\mathrm{Co}^{\mathrm{II}}$ nucleus has a $\mathrm{d}^{5}$ configuration with spin $s=1 / 2$, and a magnetic moment $M_{\mathrm{I}}=7 / 2$. The EPR spectrum comprises 8 lines as shown in Fig. 6 [17]. In spite of apparent similarities of the haem and corrin structures iron and cobalt are not biologically interchangeable. This must be due to their redox potentials being different, an important discriminatory factor in selectivity of biological electron transfer reactions [18].

A most useful technique for the study of bio-inorganic structures however is to induce electron transfer by high energy ionising radiation. We have used $\gamma$-radiation for reduction of $\mathrm{Fe}^{\mathrm{III}}$ and $\mathrm{Co}^{\mathrm{III}}$ by oneelectron gain mechanisms to their respective lower oxidation states. In the case of iron characteristic $\mathrm{Fe}^{\mathrm{III}}$ features were lost, and for cobalt the resulting $\mathrm{Co}^{\mathrm{II}}$ species were identified by their characteristic 8-line EPR spectral features [17]. 


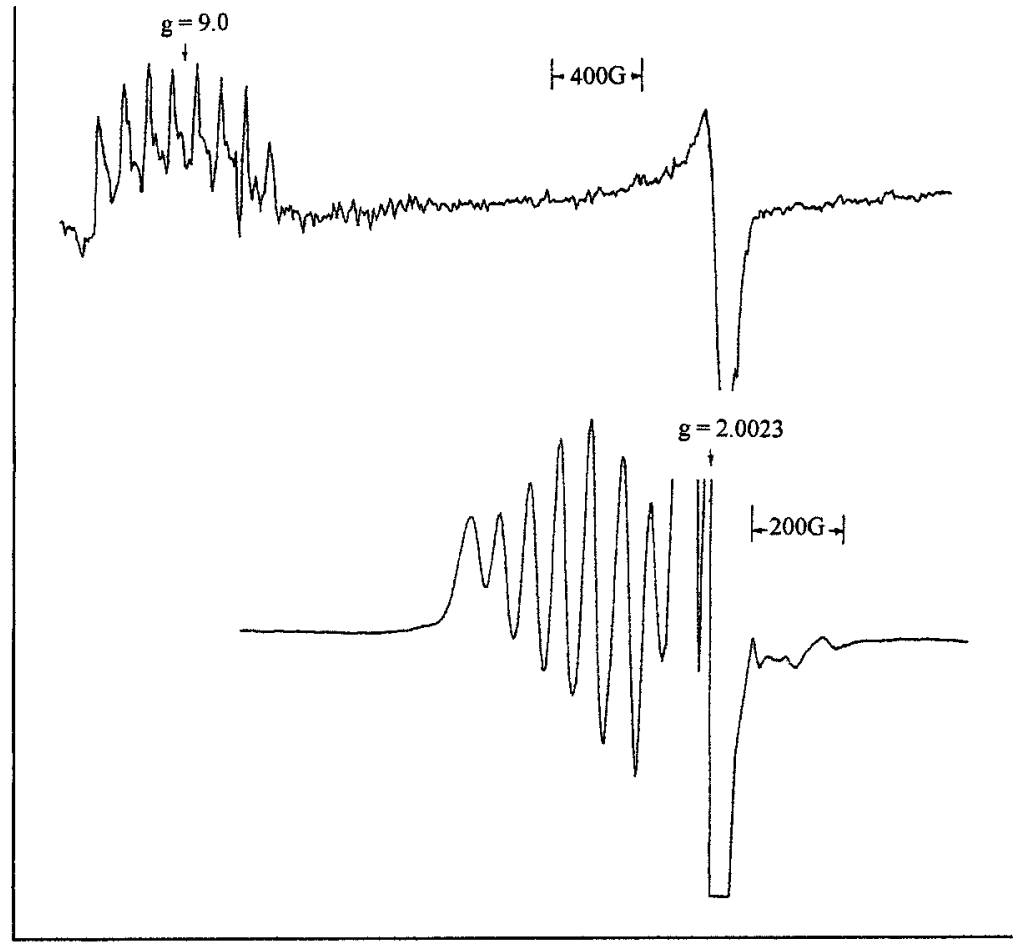

Magnetic Field /G

Fig. 6. First derivative EPR spectrum for $\mathrm{Co}^{\mathrm{II}}$ centres at $4 \mathrm{~K}$, showing features assigned to spin $s=1 / 2$ and $M_{\mathrm{I}}=7 / 2$.

\section{Electron transfer systems}

There are a large number of metalloproteins involved in electron transfer processes of which a few have been selected which seem to be of special interest. The first is methane monooxygenase, which goes back to primordial times when methane and nitrogen, rather than oxygen and nitrogen were the major compounds of the atmosphere. Next is xanthine oxidase for the interesting role played by molybdenum and $\mathrm{Fe} / \mathrm{S}$ centres in electron transfer. The third enzyme is cytochrome oxidase. This is a key part of the electron transfer system in mitochondria in which oxygen is reduced to water in such a way that there is no release of radical intermediates.

\section{Methane monooxygenase}

Methane monooxygenase (MMO) is an ancient enzyme which catalyses the conversion of $\mathrm{CH}_{4}$ stepwise into $\mathrm{CH}_{3} \mathrm{OH}, \mathrm{CH}_{2}=\mathrm{O}, \mathrm{HCO}_{2}^{-\cdot}$, and finally $\mathrm{CO}_{2}$ with great efficiency, again ensuring that any dangerous intermediates such as ${ }^{\circ} \mathrm{CH}_{3}$ radicals are not released. There are non-haem iron centres forming binuclear mixed valence species of the types $\mathrm{Fe}^{\mathrm{III}}-\mathrm{Fe}^{\mathrm{II}}$ and $\mathrm{Fe}^{\mathrm{IV}}-\mathrm{Fe}^{\mathrm{III}}$ [19]. These form the nucleus of electron transfer reactions facilitating the action of the enzyme.

On the mechanism of MMO catalysed oxidation of methane there are different mechanisms proposed, one a non-radical mechanism [20] and the other a free radical mechanism [21]. In the work using $\mathrm{CH}_{3} \mathrm{OH}$ as substrate together with spin traps to capture any radicals formed intense EPR features suggesting 
formation of a carbon centred radical were obtained. Then using ${ }^{13} \mathrm{CH}_{3} \mathrm{OH}$, extra doublet features were detected, confirming that the radicals were $\mathrm{H}_{2} \cdot \mathrm{COH}$ [22].

\section{Xanthine oxidase}

The enzyme is specially designed to convert xanthine to uric acid. This involves the transfer of two electrons from xanthine to the xanthine oxidase $\mathrm{Mo}^{\mathrm{IV}}$ centre which is reduced to $\mathrm{Mo}^{\mathrm{IV}}$ neither of which is paramagnetic. However, when electrons are released from the enzyme during turn-over, it occurs in a sequence of single electron transfers from the molybdenum centre through a relay of iron-sulphur centres to FAD. The first-formed $\mathrm{Mo}^{\mathrm{V}}$ specie is paramagnetic and therefore EPR measurable, and finally reduced to the $\mathrm{Mo}^{\mathrm{IV}}$ [23]. In the absence of any FAD oxygen occupies the binding site. This fortuitously forms $\mathrm{O}_{2}^{--}$radical anions. Spin-trapping of the superoxide radical anion formed by this method is a bench mark procedure for its generation; a technique popularly used by biochemists [24].

\section{Cytochrome oxidase}

This enzyme catalyses reduction of oxygen to water without release of any intermediate peroxide species. There are iron and copper units central to the catalysis which is an electron transfer reaction. Because of differences in the coordination spheres of the metals and their ligands, their EPR parameters are different and well distinguishable. The most measurable differences are made at very low temperatures where relaxation rates are low and as close to zero as possible. This is usually at less than $77 \mathrm{~K}$ but better still nearer $4 \mathrm{~K}$.

In this mechanism an electron is delivered by cytochrome $\mathrm{c}$ first to a $\mathrm{Cu}^{\mathrm{II}}$ unit which rapidly passes it on to a $\mathrm{Fe}^{\mathrm{III}}$ unit. It is then passed on to the $\mathrm{Fe}^{\mathrm{III}}-\mathrm{O}_{2}-\mathrm{Cu}^{\mathrm{II}}$ unit which is relatively close to the inner membrane of the cell. This generates $\mathrm{O}_{2}^{--}$radical anions some of which are protonated to give $\mathrm{HO}_{2}^{-}$. As more electrons and protons arise, $\mathrm{O}-\mathrm{O}$ bonds break and finally $\mathrm{H}_{2} \mathrm{O}$ molecules are formed in addition to $\mathrm{O}_{2}^{-}, \mathrm{HO}_{2}^{-}$, and $\mathrm{H}_{2} \mathrm{O}_{2}$. The pairs of $\mathrm{Fe}$ and $\mathrm{Cu}$ are well distinguishable by EPR and have been labeled $\mathrm{Cu}_{\mathrm{a}}, \mathrm{Cu}_{\mathrm{b}}$ and $\mathrm{Fe}_{\mathrm{a}}$ and $\mathrm{Fe}_{\mathrm{a} 3}$. The $\mathrm{H}_{3} \mathrm{O}^{+}$and $\mathrm{O}_{2}$ pass up one of two water channels that converge on the $\mathrm{Fe}-\mathrm{Cu}$ unit. They are in our view fail-safe channels in case one becomes 'blocked' mechanistically or energetically. The cytochrome $\mathrm{c}$ is regenerated, thereby generating protons and the cation continues to give $\mathrm{HO}_{2}^{-}$and $\mathrm{H}_{2} \mathrm{O}_{2}$. The next electron generates $\mathrm{OH}$ and $\mathrm{H}_{2} \mathrm{O}$ and then finally two $\mathrm{H}_{2} \mathrm{O}$ molecules.

\section{Conclusion}

We conclude that iron and to a lesser extent, copper, play key roles in many areas of biology. In many cases, they are essential to the reactions of enzymes. However, in the presence of hydrogen peroxide their reduced forms, $\mathrm{Fe}^{\mathrm{II}}$ and $\mathrm{Cu}^{\mathrm{I}}$, are destructively reactive hence they are rarely found free in solution but as protein-bound species for release only on demand. In all cases the metal ions are detectable by EPR spectroscopy provided they have unpaired electrons.

\section{Acknowledgement}

This review is dedicated to the late Martyn Symons, a man of great chemical insight, who taught me EPR spectroscopy and its application to all things living and non-living. 


\section{References}

[1] M. Symons, Chemical and Biochemical Aspects of Electron-Spin Resonance Spectroscopy, Van Nostrand Reinhold, England, 1978.

[2] J.R. Pilbrow, Transition Ion Electron Paramagnetic Resonance, Clarendon Press, Oxford, 1990.

[3] C. More, V. Belle, M. Asso, A. Fournel, G. Roger, B. Guighiarelli and P. Bertrand, Electron paramagnetic resonance spectroscopy, A powerful technique for the structural and functional investigation of metalloprotiens, Biospectroscopy $\mathbf{5}$ (1999), S3-S18.

[4] R.E. Shepherd, M.A. Sweethand and D.E. Junker, Ligand field factors in promoting $s=3 / 2\{$ FeNO $\}$ Nitrosyl, J. Inorg. Biochem. 64 (1997), 1-14.

[5] C.E. Copper, Nitric oxide and iron proteins, Biochim. Biophys. Acta 1411 (1999), 290-309.

[6] R.L. Petersen, M.C.R. Symons and F.A. Taiwo, Application of radiation and ESR spectroscopy to the study of ferryl haemoglobin, J. Chem. Soc. Faraday Trans. 185 (1989), 2435-2444.

[7] M.J.H. van Haandel, J.L. Primus, C. Teunius, M.G. Boerma, A.M. Osman, C. Veager and I.M.C.M. Rietjens, Reversible formation of high-valent-iron-oxo porphyrin intermediates in heme-base catalysis: revisiting the kinetic model for horseradish peroxidase, Inorg. Chimica Acta 275-276 (1997), 98-105.

[8] M.C.R. Symons and F.A. Taiwo, Electron transfer between $\alpha$ - and $\beta$-haem groups in haemoglobin, J. Chem. Soc., Faraday Trans. 185 (1989), 2427-2433.

[9] N. Deighton, A. Abu-Raqabah, I.J. Rowland, M.C.R. Symons, T.J. Peters and R.J. Ward, Electron paramagnetic resonance studies of a range of ferritins and haemosiderins, J. Chem. Soc. Faraday Trans 187 (1991), 3193-3197.

[10] F.A. Taiwo, P.M. Brophy, D.I. Pritchard, A. Brown, A. Wardlaw and L.H. Patterson, Comparative metal content profiling of parasitic helminths by electron paramagnetic resonance spectrometry: significance for metalloprotein content, Int. J. Parasitol. 30 (2000), 29-33.

[11] C.S. Peyratout, J.C. Severns, S.R. Holm and D.R. Millin, Electron paramagnetic resonance studies of ligand binding to the Type2/Type3 cluster in tree laccase, Arch. Biochem. Biophys. 314 (1994), 405-411.

[12] M.C.R. Symons and R.L. Petersen, Electron addition to the active sites of Cancer magister hemocyanins; An ESR study, Biochim. Biophys. Acta 536 (1978), 247-254.

[13] F.A. Taiwo, P. Kenton, L.A.J. Mur and J. Draper, Unpublished observation.

[14] A. Ivancich, V.V. Barynin and J.L. Zimmermann, Pulsed EPR studies of the binuclear $\mathrm{Mn}^{\mathrm{III}} \mathrm{Mn}^{\mathrm{IV}}$ center in catalase from Thermus thermophilus, Biochem. (1995).

[15] Y.-M. Frapert, M. Delroisse, E. AnxOlabehere-Mallar, G. Blondin, J.-J. Girerd, J.-B. Verlhac, D. Lexa, M. Cesari and C. Pascard, Two dinucler bisimidazole $\mathrm{Mn}^{\mathrm{III}}, \mathrm{Mn}^{\mathrm{IV}}$ model complexes for the manganese site in photosynthesis and manganese catalase, J. Inorg. Biochem. 59 (1995), 626-632.

[16] J.M.C. Gutteridge, Iron promoters of the Fenton reaction and lipid peroxidation can be released from haemoglobin by peroxides, FEBS Lett. 201 (1986), 291-295.

[17] M.C.R. Symons, T. Taiwo, A.M. Sargeson, M.M. Ali and A.S. El-Tabl, EPR spectra for high and low spin Co ${ }^{\mathrm{II}}$ encapsulated complexes, Inorg. Chimica Acta 241 (1996), 5-8.

[18] S.E. Peterson-Kennedy, J.L. McGourty, J.A. Kalweit and B.M. Hoffman, Temperature dependence of and ligation effecys on long range electron transfer in complexes, J. Amer. Chem. Soc. 108 (1986), 1739-1746.

[19] K. Chen, M. Costas and L. Que, Spin state tuning of non-heme iron-catalyze hydrocarbon oxidations: participation of $\mathrm{Fe}^{\mathrm{III}}-\mathrm{OOH}$ and $\mathrm{Fe}^{\mathrm{V}}=\mathrm{O}$ intermediates, J. Chem. Soc. Dalton Trans. 5 (2002), 672-679.

[20] H. Dalton, D.S. Smith and S. Pilkington, Towards a unified mechanism of biological methane oxidation, FEMS Microbiol. Rev. 87 (1990), 201-207.

[21] A.M. Valentine, M.H. Le Tadic-Biadatti, P.H. Toys, M. Newcomb and S.J. Lippard, Oxidation of ultrafast radical clock substrate probes by the soluble methane monooxygenase from Methylococus capsilatus, Biol. Chem. 274 (1999), 1077110776.

[22] P.C. Wilkins, H. Dalton, I.D. Podmore, N. Deighton and M.C.R. Symons, Biological methane activation involves the intermediacy of carbon-centered radicals, Eur. J. Biochem. 210 (1992), 67-72.

[23] M.C.R. Symons, F.A. Taiwo and R.L Petersen, Electron addition to xanthine oxidase: An ESR study of the effects of ionizing radiation, J. Chem. Soc., Faraday Trans. 185 (1989), 4063-4074.

[24] F.A. Taiwo, P.M. Brophy, D.I. Pritchard, A. Brown, A. Wardlaw and L.H. Patterson, Cu/Zn superoxide dismutase in excretory-secretory products of the human hookworm Necator americanus, Eur. J. Biochem. 264 (1999), 434-438. 


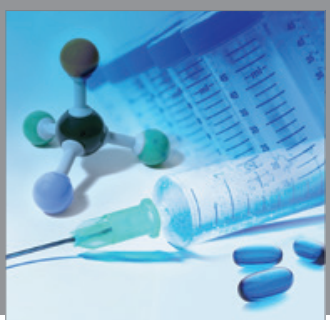

International Journal of

Medicinal Chemistry

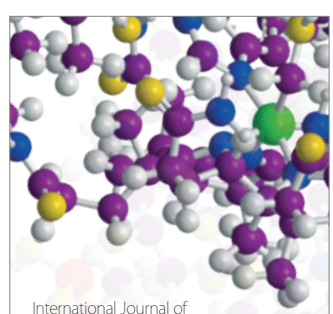

Carbohydrate Chemistry

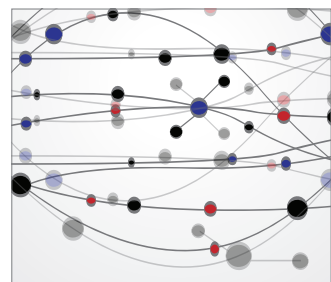

The Scientific World Journal
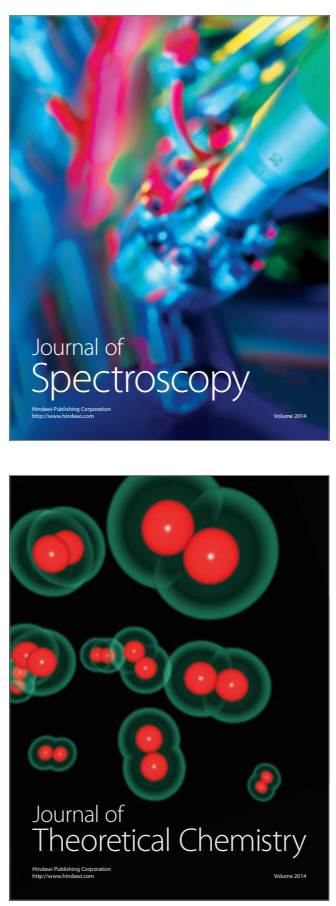
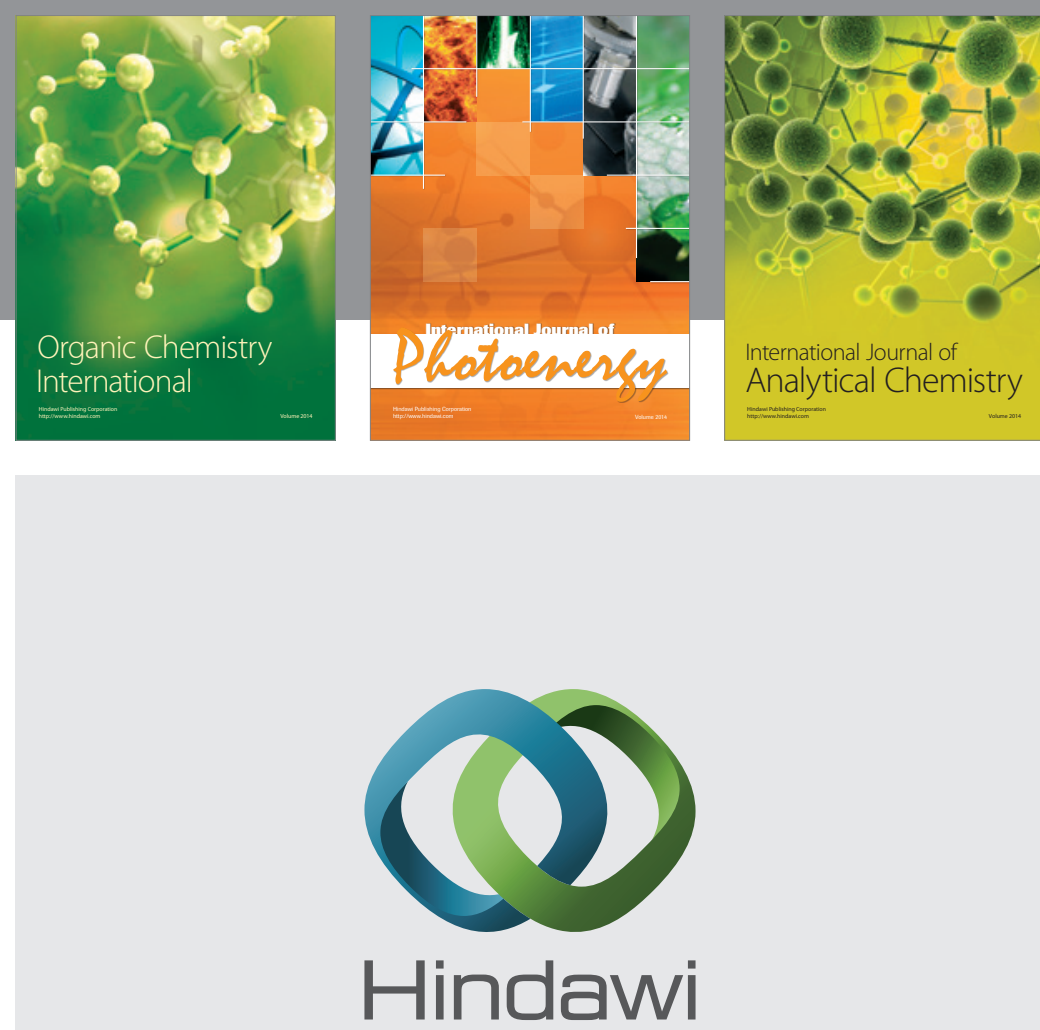

Submit your manuscripts at

http://www.hindawi.com
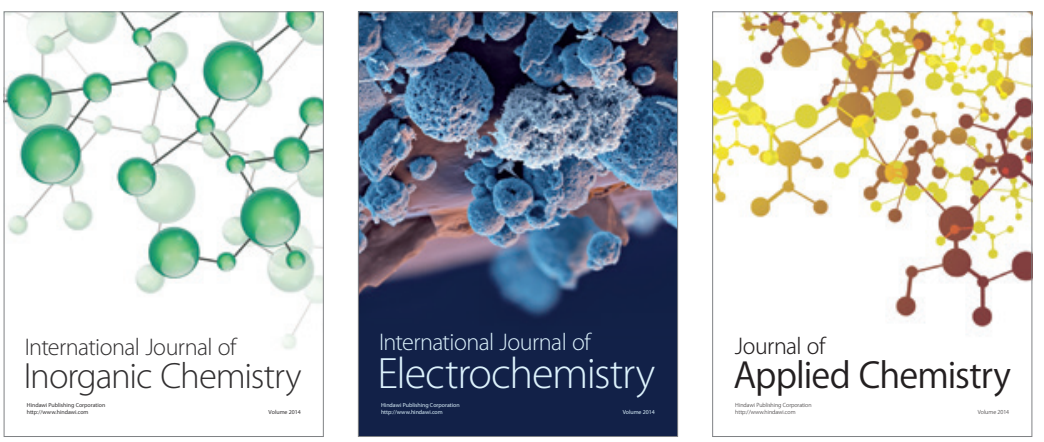

Journal of

Applied Chemistry
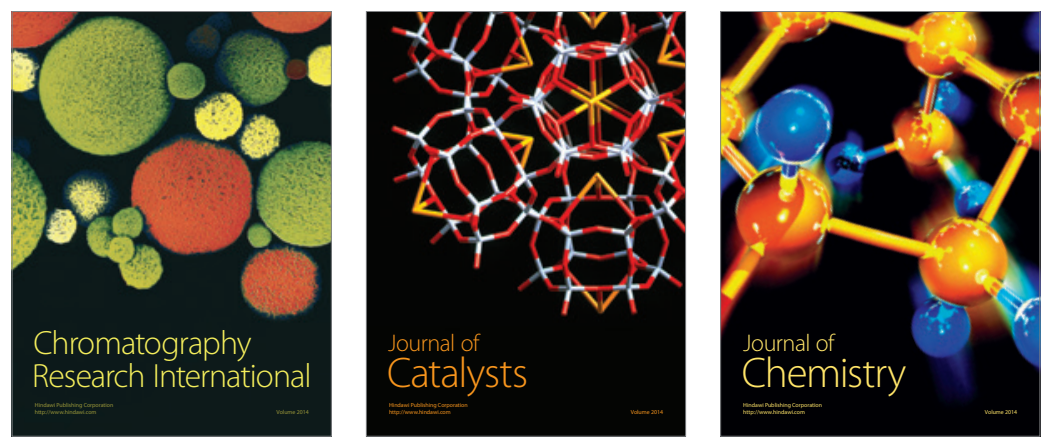
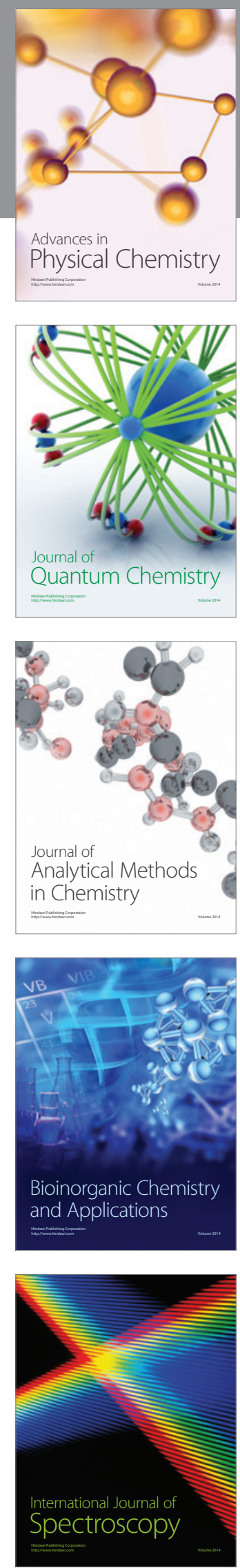